\title{
Comparative Effects of Periarticular Multimodal Drug Injection and Single-Shot Femoral Nerve Block on Pain Following Total Knee Arthroplasty and Factors Influencing Their Effectiveness
}

\author{
Shuji Nakagawa, $\mathrm{MD}^{1}$, Yuji Arai, $\mathrm{MD}^{1}$, Hiroaki Inoue, $\mathrm{MD}^{1}$, Hiroyuki Kan, $\mathrm{MD}^{1}$, Manabu Hino, $\mathrm{MD}^{1}$, \\ Shohei Ichimaru, $\mathrm{MD}^{1}$, Kazuya Ikoma, $\mathrm{MD}^{1}$, Hiroyoshi Fujiwara, $\mathrm{MD}^{1}$, Fumimasa Amaya, $\mathrm{MD}^{2}$, \\ Teiji Sawa, $\mathrm{MD}^{2}$, and Toshikazu Kubo, $\mathrm{MD}^{1}$ \\ Departments of ${ }^{1}$ Orthopaedics and ${ }^{2}$ Anesthesiology, Graduate School of Medical Science, Kyoto Prefectural University of Medicine, Kyoto, Japan
}

\begin{abstract}
Purpose: This study compared the analgesic effects of local infiltration analgesia (LIA) and femoral nerve block (FNB) after total knee arthroplasty (TKA) and assessed factors associated with analgesia obtained by these two methods.

Materials and Methods: Study subjects included 66 patients (72 knees) who underwent TKA for osteoarthritis of the knee. Pain visual analogue scale (VAS), the amount of analgesics used, number of days to achieve $90^{\circ}$ of flexion of the knee joint, date of initiating parallel-bar walking, range of motion of the knee joint at discharge, and adverse events were investigated.

Results: The VAS scores did not differ significantly between two groups, whereas the amount of analgesics used was significantly lower in the LIA group. Preoperative flexion contracture was significantly more severe in the LIA group with high VAS compared with low VAS. No serious adverse event occurred in the LIA or FNB group.

Conclusions: The lower analgesic usage in the LIA group than the FNB group indicates that the analgesic effect of LIA was greater than that of singleshot FNB after TKA. There were no serious complications in either group. The postoperative analgesic effect of LIA was smaller in patients with severe than less severe preoperative flexion contracture.
\end{abstract}

Keywords: Knee, Arthroplasty, Femoral nerve block, Local infiltration analgesia, Flexion contracture

\section{Introduction}

Total knee arthroplasty (TKA) improves joint function in patients with painful joint disease and reduces pain ${ }^{1,2)}$. The clinical outcomes of TKA have improved over time, and the 10-year re-

Received January 5, 2016; Revised (1st) February 8, 2016;

(2nd) March 14, 2016; Accepted March 27, 2016

Correspondence to: Yuji Arai, MD

Department of Orthopaedics, Graduate School of Medical Science,

Kyoto Prefectural University of Medicine, 465 Kajiicho, Kawaramachi-

Hirokoji, Kamigyo-ku, Kyoto 602-8566, Japan

Tel: +81-75-251-5549, Fax: +81-75-251-5841

E-mail: yarai89046@nike.eonet.ne.jp

This is an Open Access article distributed under the terms of the Creative Commons Attribution Non-Commercial License (http://creativecommons.org/licenses/by-nc/4.0/) which permits unrestricted non-commercial use, distribution, and reproduction in any medium, provided the original work is properly cited. vision-free survival rate has been reported to range from $96 \%$ to $98 \%{ }^{3-5)}$. However, TKA has been found to induce the most severe postoperative pain among all orthopedic surgical procedures, with severe pain during the acute phase thought to cause chronic pain $^{6,7)}$. Therefore, TKA without postoperative pain is an important perioperative goal $^{7)}$.

Postoperative methods for analgesia after TKA include epidural anesthesia, local infiltration analgesia (LIA), and femoral nerve block $(\mathrm{FNB})^{8-10)}$. Although epidural anesthesia has good analgesic effects, it limits the use of anticoagulants against lower limb deep venous thrombosis and can lead to adverse events, such as nausea and vomiting. LIA and FNB are simple methods that lead to fewer complications. Although both have shown favorable postoperative analgesic effects, they have not been directly compared. Moreover, the analgesic effect of these procedures may not be consistent. Perception of pain in the knee joint involves both the femoral 
and sciatic nerves. LIA and FNB differ in their effects on these nerves because LIA involves an injection into the entire knee joint, whereas FNB has analgesic effects only in the femoral nerve area. In this study, under the hypothesis that the analgesic effect of LIA would be superior to that of FNB, we compared the analgesic effects of LIA and the single-shot FNB after TKA and attempted to identify factors associated with their analgesic effects.

\section{Materials and Methods}

This study was approved by the Kyoto Prefectural University of Medicine Review Board (ERB-C-3-2). The subjects consisted of 66 patients ( 72 knees; 15 knees in 14 males and 57 knees in 52 females) who underwent TKA for osteoarthritis of the knee at our hospital between December 2012 and August 2014. Patients were excluded if they had a primary constrained prosthesis, rheumatoid arthritis, osteonecrosis, valgus knee, or underwent surgery with epidural anesthesia. Patients undergoing surgery on odd days received LIA and those who underwent surgery on even days received FNB. LIA, consisting of $5 \mathrm{mg}$ of morphine, $150 \mathrm{mg}$ of $0.75 \%$ ropivacaine, $0.3 \mathrm{mg}$ of epinephrine, and $4 \mathrm{mg}$ of betamethasone diluted in $50 \mathrm{~mL}$ of saline, was administered by the operator after completion of all femoral and tibial osteotomy steps, immediately before cement fixation of the implant. The LIA solution was injected into the tissues around the joint, i.e., the posterior articular capsule of the knee joint, patellar retinaculum, subcutaneous tissue, and pes anserinus. Using an electric stimulator, single-shot $\mathrm{FNB}$, consisting of $150 \mathrm{mg}$ of $0.75 \%$ ropivacaine, was administered by an anesthesiologist under echo guidance to the inguinal region above the femoral nerve upon completion of surgery.

General anesthesia was induced by administration of propofol and fentanyl and maintained with sevoflurane and fentanyl. Surgery was performed using the posterior stabilized (PS)-type model of NexGen LPS-flex (Zimmer, Warsaw, IN, USA) or Scorpio NRG (Stryker, Mahwah, NJ, USA) and the parapatellar approach. As a tourniquet has been reported to reduce early postoperative pain, a tourniquet was applied immediately before fixation of the prosthesis until completion of skin sutures ${ }^{11)}$. A drainage tube was placed in the knee joint at surgery and removed two days later. On the day after surgery, early postoperative ambulation, range of motion training, and quadriceps muscle training were performed in response to pain. Whenever possible, parallel bar walking was started on postoperative day 4 . Cane assisted walking was permitted about 2 weeks after surgery and stair climbing at 3 weeks after surgery.
All patients received $60 \mathrm{mg}$ of loxoprofen sodium every 8 hours after surgery. The rescue analgesic consisting of 25 or $50 \mathrm{mg}$ of diclofenac, depending on pain severity, was administered as a suppository. The total amount of diclofenac administered was defined as the amount of analgesics used. Pain was evaluated from the day of surgery to 5 days after surgery using a visual analogue scale (VAS). The pain VAS consisted of a line, $10 \mathrm{~cm}$ in length, on which patients indicated current pain from 0 (no pain) to 10 (worst possible pain). Other parameters recorded included times (days) to $90^{\circ}$ of knee joint flexion, parallel-bar walking, and T-cane walking; range of motion (flexion and extension) of the knee joint at the time of discharge; length of hospital stay; and adverse events. As one study reported that almost all patients with severe pain had VAS scores of $>54 \mathrm{~mm}$, with a mean score of $75 \mathrm{~mm}^{12)}$, patients with postoperative VAS scores of $<54$ for 5 days after surgery were designated as the low VAS group, and those with VAS scores of $\geq 54$ at least once were designated as the high VAS group. Age, sex ratio, body mass index, preoperative VAS, preoperative femorotibial angle (FTA), preoperative range of motion of the knee joint (flexion and extension angles), and preoperative knee score were compared within each group (LIA and FNB) between patients with VAS scores of $<54$ and those with VAS scores of $\geq 54^{13)}$. The FTA was defined as the lateral angle between the femoral axis and the tibial axis. Intraoperative factors compared included operation time, defined as the time from skin incision to the end of wound closure, and blood loss (intraoperative drainage), as measured with gauze and a suction tube.

\section{Statistical Analysis}

Measurements were expressed as mean \pm standard deviation. Outcomes in the LIA and FNB groups were compared using Mann-Whitney $U$ tests for VAS; amount of diclofenac sodium used; numbers of days to achieve $90^{\circ}$ knee flexion, initiation of parallel-bar walking, and T-cane walking; and range of motion (flexion and extension) of the knee joint at the time of discharge. Patient characteristics, operation time, and blood loss were compared in the low and high VAS groups using Mann-Whitney U-test. Factors independently associated with high VAS were determined by a stepwise multivariate logistic regression analysis. The available data were assessed by a power analysis with an alpha level of 0.05. All statistical analyses were performed using IBM SPSS ver. 21.0 (IBM Co., Armonk, NY, USA), with $\mathrm{p}<0.05$ defined as statistically significant. 


\section{Results}

Pain VAS scores were similar between the LIA and FNB groups on days 0-5 after surgery (Fig. 1). The mean dosage of diclofenac per patient was significantly lower in the LIA group than in the FNB group ( $34 \pm 45 \mathrm{mg}$ vs. $56 \pm 45 \mathrm{mg} ; \mathrm{p}=0.048$ ) (Table 1 ). Times to achieve $90^{\circ}$ flexion of the knee joint ( $2.7 \pm 1.3$ days vs. $2.3 \pm 1.2$ days; $\mathrm{p}=0.19)$, to initiate parallel-bar walking ( $4.1 \pm 1.3$ days vs. $3.9 \pm 1.0$ days; $\mathrm{p}=0.57)$, to start $\mathrm{T}$-cane walking $(13.6 \pm 3.9$ days vs. $13.9 \pm 4.0$ days; $\mathrm{p}=0.75)$, and to discharge ( $36.0 \pm 6.2$ days vs. $34.6 \pm 6.9$ days; $\mathrm{p}=0.39$ ) were similar between the LIA group and FNB group. Assessment of ranges of motion at discharge showed similar results between the two groups for extension $\left(-2.0^{\circ} \pm 3.1^{\circ}\right.$ vs. $\left.3.4^{\circ} \pm 4.5^{\circ} ; \mathrm{p}=0.14\right)$ and flexion $\left(124.6^{\circ} \pm 11.3^{\circ}\right.$ vs. $124.8^{\circ} \pm 7.4^{\circ}$; $\mathrm{p}=0.95$ ). Adverse events in the LIA group included nausea in five patients and itching and chest discomfort in one each. Adverse

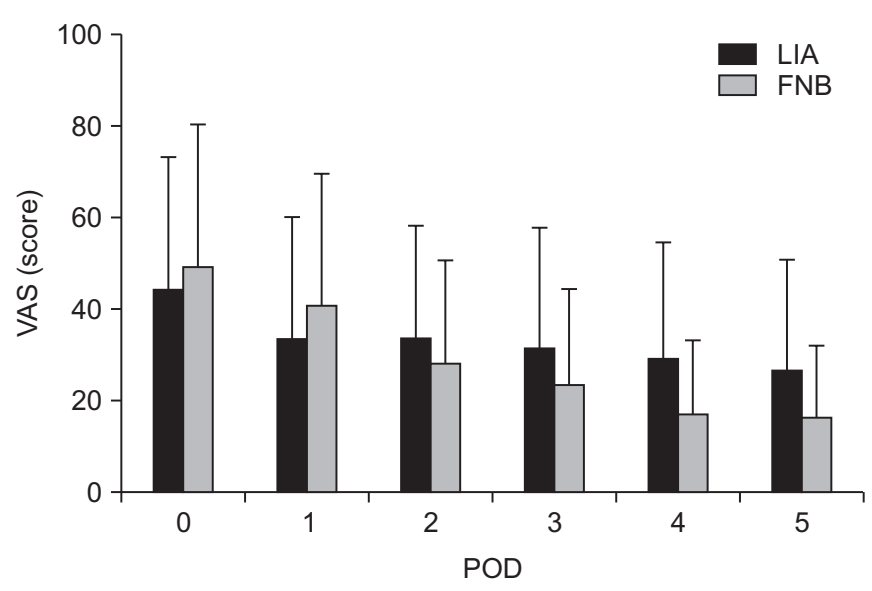

Fig. 1. Pain visual analog scale (VAS) score from the day of surgery to postoperative day (POD) 5 in the local infiltration analgesia (LIA) and femoral nerve block (FNB) groups. Both groups showed significant improvements in pain scores, and there were no significant differences between the two groups. The error bars indicate standard deviation. events in the FNB group included nausea in three patients and numbness of the region innervated by the femoral nerve in two. No patient in either group experienced a serious adverse event, such as respiratory inhibition, infection, nerve palsy, or local anesthetic intoxication.

The low VAS group with a high analgesic effect included 37 knees: 25 treated with LIA and 12 with FNB; whereas the high VAS group with a low analgesic effect included 35 knees: 19 treated with LIA and 16 with FNB $(p=0.24)$. The demographic and clinical characteristics of these two groups are summarized in Tables 2 and 3. A comparison of the LIA-treated patients with low and high VAS scores showed significant differences in sex ratio and preoperative range of extension (Table 4). Preoperative VAS score was similar in the LIA group with low and high postoperative VAS scores (47.1 \pm 31.1 vs. $46.1 \pm 30.1$; $\mathrm{p}=0.93)$. Of these LIA-treated patients, two males and 23 females had low VAS scores, and six males and 13 females had high VAS scores $(\mathrm{p}=0.04)$. The preoperative ranges of extension in these two subgroups were $-5.2^{\circ}$ and $-9.0^{\circ}$, respectively $(p=0.03)$, whereas their postoperative ranges of extension were $-1.8^{\circ}$ and $-2.4^{\circ}$, respectively ( $\mathrm{p}=0.66$ ). A comparison of the FNB-treated patients with low and high postoperative VAS scores showed no significant differences in any demographic or clinical factors.

The available data were assessed by a power analysis with the power ranging from $5.0 \%$ to $54.3 \%$ (Table 5).

\section{Discussion}

The objective of this study was to compare the analgesic effects of LIA and single-shot FNB after TKA and to retrospectively examine factors influencing these analgesic effects. The dosage of diclofenac was significantly lower in the LIA group than in the FNB group. Male gender and preoperative limited range of extension were associated with high postoperative VAS scores in the

Table 1. Comparison between the Local Infiltration Analgesia (LIA) Group and the Femoral Nerve Block (FNB) Group

\begin{tabular}{lccc}
\hline \multicolumn{1}{c}{ Variable } & LIA group & FNB group & p-value \\
\hline Amount of analgesics used $(\mathrm{mg})$ & $34 \pm 44.8$ & $56 \pm 45$ & $0.048^{\mathrm{a})}$ \\
No. of days to achieve $90^{\circ}$ of flexion the knee joint & $2.7 \pm 1.3$ & $2.3 \pm 1.2$ & 0.19 \\
Days to initiate parallel-bar walking & $4.1 \pm 1.3$ & $3.9 \pm 1.0$ & 0.57 \\
Days to initiate T-cane walking & $13.6 \pm 3.9$ & $13.9 \pm 4.0$ & 0.75 \\
Range of extension on discharge $\left(^{\circ}\right)$ & $-2.0 \pm 3.1$ & $-3.4 \pm 4.5$ & 0.14 \\
Flexion $\left(^{\circ}\right)$ & $124.6 \pm 11.3$ & $124.8 \pm 7.4$ & 0.95 \\
Length of hospital stay (day) & $36.0 \pm 6.2$ & $34.6 \pm 6.9$ & 0.39 \\
\hline
\end{tabular}

Values are presented as mean \pm standard deviation.

a) The mean dosage of diclofenac per patient was significantly lower in the LIA group than in the FNB group. 
Table 2. Characteristics of the Local Infiltration Analgesia Group Classified according to Pain VAS Score

\begin{tabular}{lccc}
\hline \multicolumn{1}{c}{ Characteristic } & $\begin{array}{c}\text { Low VAS group } \\
(25 \text { knees })\end{array}$ & $\begin{array}{c}\text { High VAS group } \\
(19 \text { knees })\end{array}$ & p-value \\
\hline Age (yr) & $74.5 \pm 7.8$ & $73.2 \pm 9.4$ & 0.10 \\
Sex (M:F) & $2: 23$ & $6: 13$ & 0.04 \\
Body mass index $\left(\mathrm{kg} / \mathrm{m}^{2}\right)$ & $25.5 \pm 4.1$ & $24.4 \pm 3.1$ & 0.34 \\
Preoperative FTA $\left({ }^{\circ}\right)$ & $186 \pm 7.7$ & $185 \pm 3.9$ & 0.77 \\
Preoperative range of & $-5.2 \pm 4.1$ & $-9.0 \pm 6.2$ & 0.02 \\
$\quad$ extension $\left({ }^{\circ}\right)$ & & & \\
Flexion $\left({ }^{\circ}\right)$ & $125 \pm 13.7$ & $123 \pm 17.6$ & 0.64 \\
Preoperative knee score & $54.2 \pm 10.6$ & $56.1 \pm 15.2$ & 0.76 \\
Operative time (min) & $148 \pm 25$ & $144 \pm 24$ & 0.60 \\
Blood loss $(\mathrm{mL})$ & $285 \pm 128$ & $342 \pm 118$ & 0.15 \\
\hline
\end{tabular}

Values are presented as mean \pm standard deviation.

VAS: visual analogue scale, FTA: femorotibial angle.

Table 3. Characteristics of the Femoral Nerve Block Group Classified according to Pain VAS Score

\begin{tabular}{lccc}
\hline \multicolumn{1}{c}{ Characteristic } & $\begin{array}{c}\text { Low VAS group } \\
(12 \text { knees })\end{array}$ & $\begin{array}{c}\text { High VAS group } \\
(16 \text { knees })\end{array}$ & p-value \\
\hline Age $(\mathrm{yr})$ & $74.5 \pm 7.0$ & $71.9 \pm 8.9$ & 0.45 \\
Sex $(\mathrm{M}: \mathrm{F})$ & $1: 11$ & $5: 11$ & 0.89 \\
Body mass index $\left(\mathrm{kg} / \mathrm{m}^{2}\right)$ & $26.0 \pm 3.4$ & $26.6 \pm 4.0$ & 0.45 \\
Preoperative FTA $\left({ }^{\circ}\right)$ & $183 \pm 7.8$ & $185 \pm 8.1$ & 0.94 \\
Preoperative range of & $-5.8 \pm 4.0$ & $-10.6 \pm 8.8$ & 0.61 \\
$\quad$ extension $\left({ }^{\circ}\right)$ & & & \\
Flexion $\left({ }^{\circ}\right)$ & $130 \pm 9$ & $121 \pm 15$ & 0.23 \\
Preoperative knee score & $60.8 \pm 14.6$ & $54.3 \pm 15.0$ & 0.30 \\
Operative time $(\mathrm{min})$ & $151 \pm 20$ & $156 \pm 35$ & 0.20 \\
Blood loss $(\mathrm{mL})$ & $279 \pm 137$ & $428 \pm 150$ & 0.89 \\
\hline
\end{tabular}

Values are presented as mean \pm standard deviation.

VAS: visual analogue scale, FTA: femorotibial angle.

LIA group, indicating that the postoperative analgesic effects of LIA were smaller in patients with more severe flexion contracture before surgery and in male than female patients.

TKA is a superior reconstruction method for knee joint function, and long-term outcomes have improved and stabilized over time. Evaluations of the postoperative outcomes of TKA have included both long-term survival of the implant as well as patient satisfaction. Patient satisfaction has been reported lower after TKA than after total hip arthroplasty due to postoperative pain $^{14-16)}$. Perioperative pain is of concern for patients, and sufficient analgesic countermeasures are necessary. Several recent studies evaluating the analgesic effects of LIA and FNB have
Table 4. Multiple Logistic Regression Analysis of Factors Significantly Associated with Pain after Total Knee Arthroplasty ${ }^{\text {a) }}$

\begin{tabular}{lccc}
\hline \multicolumn{1}{c}{ Risk factor } & $\begin{array}{c}\text { Odds } \\
\text { ratio }\end{array}$ & $\begin{array}{c}95 \% \text { confidence } \\
\text { interval }\end{array}$ & p-value \\
\hline Sex (male) & 6.918 & $1.079-44.36$ & 0.041 \\
Preoperative range of extension $\left({ }^{\circ}\right)$ & 0.851 & $0.736-0.984$ & 0.029 \\
\hline
\end{tabular}

${ }^{a)}$ Male (vs. female) sex and preoperative range of extension were significantly associated with high visual analog scale score.

Table 5. Contribution of Each Clinical Factor to Study Power

\begin{tabular}{lc}
\hline \multicolumn{1}{c}{ Variable } & $\begin{array}{c}\text { Power of the } \\
\text { study }(\%)\end{array}$ \\
\hline Amount of analgesics used & 54.3 \\
No. of days to achieve $90^{\circ}$ of flexion the knee joint & 25.6 \\
Days to initiate parallel-bar walking & 10.3 \\
Days to initiate T-cane walking & 5.0 \\
Range of extension on discharge $\left({ }^{\circ}\right)$ & 21.3 \\
Flexion $\left({ }^{\circ}\right)$ & 5.0 \\
Length of hospital stay (day) & 33.9 \\
\hline
\end{tabular}

reported conflicting results, with one finding that the analgesic effect of LIA was superior and the other finding that FNB was superior ${ }^{17,18}$. This study found equivalent pain VAS scores in the two groups, whereas analgesic dosage was lower in the LIA group than in the FNB group, suggesting that LIA has a greater analgesic effect than FNB. The superior analgesic effect of LIA may be due to the inaccessibility of FNB to the sciatic nerve area. When combined with sciatic nerve block, however, LIA and FNB provided similar pain relief after $\mathrm{TKA}^{19)}$. These findings suggest that LIA has analgesic effects on areas of both the femoral and sciatic nerves.

Severe preoperative pain in females and in young patients were found to predict pain after $\mathrm{TKA}^{20)}$, but intraoperative factors were not evaluated. We observed no significant differences in intraoperative factors between groups of patients with low and high VAS scores. Although analgesic effect was lower in male than in female patients, analgesia was not significantly associated with age or preoperative pain. In agreement with previous results, we found that pain after TKA was more severe in female than in male patients ${ }^{21}$.

Preoperative limitation of extension was significantly more severe in patients with high than low preoperative VAS scores who underwent LIA. After surgery, however, extension angle improved to within $-5^{\circ}$ in both groups, with no significant difference between groups. These findings suggest that postopera- 
tive pain increases as severe preoperative flexion contracture improves after surgery, thus reducing the effect of LIA. The effect of LIA was reduced when flexion contracture was significantly improved. Flexion contracture has been reported to be caused by contracture of the posterior cruciate ligament (PCL), posterior femoral osteophyte, posterior articular capsule, and musculotendinous tissue, such as the hamstring ${ }^{22)}$. We used PS-type implants in all knees and resected the PCL during surgery. The posterior femoral osteophyte was resected when osteotomy was performed on the posterior femoral malleolus, followed by dissection of the posterior articular capsule. Thus, it is unlikely that these treatments contributed to the difference between the two groups in postoperative analgesic effect. However, musculotendinous tissue posterior to the knee joint, such as the hamstring, was not treated surgically. In patients with severe preoperative flexion contracture, these tissues were likely stretched markedly after surgery, resulting in severe postoperative pain and reducing the analgesic effect.

This study showed that the dosage of analgesics used after surgery was lower in the LIA than in the FNB group and that it is necessary to increase analgesia after TKA in male patients and in patients with knees showing flexion contracture. A cadaver study found that injection of $60 \mathrm{~mL}$ India ink infiltrated into posterior knee joint tissue ${ }^{23)}$. Modification of the analgesic method, such as an increase in the volume of posteriorly injected LIA, may be necessary for knees with flexion contracture.

This study had a limitation. Primarily, it was underpowered to detect a statistically significant difference between the effects of LIA and FNB. Additional studies, using greater numbers of subjects, are, therefore, needed.

\section{Conclusions}

A comparison of the analgesic effects of LIA and FNB after TKA found that the dosage of concomitantly administered analgesics was lower in the LIA group, suggesting that LIA was superior to FNB as analgesia after TKA. LIA is very simple to administer, with fewer complications. No serious complications were associated with LIA or FNB. The postoperative analgesic effect of LIA was lower in patients with more severe flexion contracture before surgery and in male than in female patients.

\section{Conflict of Interest}

No potential conflict of interest relevant to this article was reported.

\section{References}

1. Ethgen O, Bruyere O, Richy F, Dardennes C, Reginster JY. Health-related quality of life in total hip and total knee arthroplasty: a qualitative and systematic review of the literature. J Bone Joint Surg Am. 2004;86:963-74.

2. Rhee SJ, Hong SM, Suh JT. High-flexion total knee arthroplasty using NexGen LPS-Flex system: minimum 5-year follow-up results. Knee Surg Relat Res. 2015;27:156-62.

3. Malkani AL, Rand JA, Bryan RS, Wallrichs SL. Total knee arthroplasty with the kinematic condylar prosthesis. A tenyear follow-up study. J Bone Joint Surg Am. 1995;77:423-31.

4. Laskin RS. The Genesis total knee prosthesis: a 10-year followup study. Clin Orthop Relat Res. 2001;(388):95-102.

5. Ritter MA, Berend ME, Meding JB, Keating EM, Faris PM, Crites BM. Long-term followup of anatomic graduated components posterior cruciate-retaining total knee replacement. Clin Orthop Relat Res. 2001;(388):51-7.

6. Giuffre M, Asci J, Arnstein P, Wilkinson C. Postoperative joint replacement pain: description and opioid requirement. J Post Anesth Nurs. 1991;6:239-45.

7. Puolakka PA, Rorarius MG, Roviola M, Puolakka TJ, Nordhausen K, Lindgren L. Persistent pain following knee arthroplasty. Eur J Anaesthesiol. 2010;27:455-60.

8. Choi PT, Bhandari M, Scott J, Douketis J. Epidural analgesia for pain relief following hip or knee replacement. Cochrane Database Syst Rev. 2003;(3):CD003071.

9. Kerr DR, Kohan L. Local infiltration analgesia: a technique for the control of acute postoperative pain following knee and hip surgery: a case study of 325 patients. Acta Orthop. 2008;79:174-83.

10. Jacob AK, Mantilla CB, Sviggum HP, Schroeder DR, Pagnano MW, Hebl JR. Perioperative nerve injury after total knee arthroplasty: regional anesthesia risk during a 20-year cohort study. Anesthesiology. 2011;114:311-7.

11. Liu D, Graham D, Gillies K, Gillies RM. Effects of tourniquet use on quadriceps function and pain in total knee arthroplasty. Knee Surg Relat Res. 2014;26:207-13.

12. Collins SL, Moore RA, McQuay HJ. The visual analogue pain intensity scale: what is moderate pain in millimetres? Pain. 1997;72:95-7.

13. Insall JN, Dorr LD, Scott RD, Scott WN. Rationale of the Knee Society clinical rating system. Clin Orthop Relat Res. 1989;(248):13-4.

14. Baker PN, van der Meulen JH, Lewsey J, Gregg PJ; National Joint Registry for England and Wales. The role of pain and 


\section{Nakagawa et al. Comparison of Periarticular Multimodal Drug Injection and Femoral Nerve Block}

function in determining patient satisfaction after total knee replacement: data from the National Joint Registry for England and Wales. J Bone Joint Surg Br. 2007;89:893-900.

15. Bourne RB, Chesworth B, Davis A, Mahomed N, Charron K. Comparing patient outcomes after THA and TKA: is there a difference? Clin Orthop Relat Res. 2010;468:542-6.

16. Kim SJ, Bamne A, Song YD, Kang YG, Kim TK. Patients still wish for key improvements after total knee arthroplasty. Knee Surg Relat Res. 2015;27:24-33.

17. Ashraf A, Raut VV, Canty SJ, McLauchlan GJ. Pain control after primary total knee replacement: a prospective randomised controlled trial of local infiltration versus single shot femoral nerve block. Knee. 2013;20:324-7.

18. Carli F, Clemente A, Asenjo JF, Kim DJ, Mistraletti G, Gomarasca M, Morabito A, Tanzer M. Analgesia and functional outcome after total knee arthroplasty: periarticular infiltration vs continuous femoral nerve block. Br J Anaesth. 2010;105:185-95.

19. Spangehl MJ, Clarke HD, Hentz JG, Misra L, Blocher JL, Seamans DP. The Chitranjan Ranawat Award: periarticular injections and femoral \& sciatic blocks provide similar pain relief after TKA: a randomized clinical trial. Clin Orthop Relat Res. 2015;473:45-53.

20. Thomas T, Robinson C, Champion D, McKell M, Pell M. Prediction and assessment of the severity of postoperative pain and of satisfaction with management. Pain. 1998;75:177-85.

21. Liu SS, Buvanendran A, Rathmell JP, Sawhney M, Bae JJ, Moric M, Perros S, Pope AJ, Poultsides L, Della Valle CJ, Shin NS, McCartney CJ, Ma Y, Shah M, Wood MJ, Manion SC, Sculco TP. A cross-sectional survey on prevalence and risk factors for persistent postsurgical pain 1 year after total hip and knee replacement. Reg Anesth Pain Med. 2012;37:415-22.

22. Su EP. Fixed flexion deformity and total knee arthroplasty. J Bone Joint Surg Br. 2012;94(11 Suppl A):112-5.

23. Quinn M, Deakin AH, McDonald DA, Cunningham IK, Payne AP, Picard F. An anatomic study of local infiltration analgesia in total knee arthroplasty. Knee. 2013;20:319-23. 